\title{
Attitudes Toward Chemistry Among 11th Grade Students in High Schools in Greece
}

\author{
KATERINA SALTA, CHRYSSA TZOUGRAKI \\ University of Athens, Athens, Greece
}

Received 18 December 2002; revised 20 June 2003; accepted 14 July 2003

DOI 10.1002/sce.10134

Published online 26 April 2004 in Wiley InterScience (www.interscience.wiley.com).

\begin{abstract}
The development of valid and reliable instruments for attitudes' measurement has been proven crucial for the quality of research. This study is dealing with the development and validation of an attitude toward chemistry instrument. By using this instrument, 11th grade Greek students' attitudes regarding the difficulty, the interest, the usefulness of chemistry course, and the importance of chemistry were investigated. Gender and study specialization differences in students' attitudes toward chemistry were examined for this population. Report card grades for the chemistry course were used to measure students' achievement in chemistry and its correlation with students' attitudes toward chemistry was explored. () 2004 Wiley Periodicals, Inc. Sci Ed 88:535-547, 2004
\end{abstract}

\section{INTRODUCTION}

Chemistry was developed greatly throughout the 20th century. An outcome of this development was the introduction of chemistry in the curriculum of elementary and secondary education, either as part of science courses or as separate discipline. Science educators have agreed that the development of a positive attitude toward science should be an important goal of the school curriculum (Aiken \& Aiken, 1969; Koballa, 1988; Laforgia, 1988).

Although there is a wide range of attitudes' definitions, all of them agree that an attitude is the tendency to think, feel, or act positively or negatively toward objects in our environment (Eagly \& Chaiken, 1993; Petty, 1995). Social psychologists have long viewed attitudes as having three components: the cognitive, the affective, and the behavioral. The cognitive component is a set of beliefs about the attributes of the attitudes' object and its assessment is performed using paper-and-pencil tests (questionnaires). The affective component includes feelings about object and its assessment is performed using psychological indices (heart rate). Finally, the behavioral component pertains to the way people act toward the object and its assessment is performed with directly observed behaviors (Eagly \& Chaiken, 1993). 
As it concerns attitudes toward science, Gardner (1975a) defined them "as a learned predisposition to evaluate in certain ways objects, people, actions, situations, or propositions involved in learning science." Attitudes toward science involve an attitude object such as "science" or "science lessons," "laboratory work" and so on (Schibeci, 1983).

Koballa and Crawley (1985) suggested that attitude toward science might be viewed "as a learned, positive, or negative feeling about science that serves as a convenient summary of a wide variety of beliefs about science" and stated that "it is important because it permits the prediction of science related behavior." Statements such as "I like science," or "I hate science," are considered to be expressions of attitudes toward science because they denote a general positive or negative feeling toward the formal study of science or science as an area of research (Koballa \& Crawley, 1985).

The attitudes of students toward science have been extensively studied. The general conclusions from the research until 1998, as reviewed by Ramsden (1998), are as follows:

- Science is considered to be difficult and not relevant to the lives of most people

- Science is supposed to cause social and environmental problems

- Science is more attractive to males than females

- The interest in science decreases over the years of secondary schooling

- The more negative views are associated with the physical sciences rather than biological sciences.

The interest of earlier studies has been focused on the issue of gender differences in science-related attitudes. The majority of studies demonstrate that boys record a more positive attitude toward science than girls (Francis \& Greer, 1999; Jones, Howe, \& Rua, 2000; O'Brien \& Porter, 1994; Schibeci \& Riley, 1986; Simpson \& Oliver, 1985). On the other hand, Greenfield (1996) found no gender differences in science-related attitudes between boys and girls.

Another finding from the previous research is the low up to moderate correlation between attitude and achievement (Freedman, 1997; Germann, 1988; Haladyna \& Shauhnessy, 1982; Wilson, 1983). From a meta-analysis covering literature from 1970 to 1991 , evidence was found that high-performing girls, "doing well" or "achieving" in science was closely linked with "liking" science (Weinburgh, 1995). The correlation between attitude and achievement for boys and girls as a function of science discipline indicated that for biology and physics the correlation is positive for both, but stronger for girls than for boys.

An important issue is the relationship between students' attitudes and instructional contexts. Do different instructional contexts influence students' attitudes and do different attitudes result in different opportunities for learning and achievement? Research from different countries with different educational systems and curricula will provide an opportunity to identify the relationship between students' attitudes and instructional contexts of these countries.

The majority of the existing studies concern attitudes toward science in general. Only few have studied attitudes toward a particular discipline like biology and physics and only two toward chemistry (Menis, 1983, 1989). Taking into consideration all the above, we decided to investigate the attitudes toward chemistry among the Greek students. We present here the results of our study.

\section{PROBLEMS ASSOCIATED WITH EVALUATION OF ATTITUDES}

Laforgia (1988) reported three main types of problems associated with measurements of attitudes toward science using closed item questionnaire, as Likert scales: 
i. Fakability

ii. Semantic problems

iii. Criterion inadequacy.

Fakability could occur if students' responses are influenced by their desire to satisfy the expectations of the researcher. This may be a problem particularly with Likert scales, which tend to expose the intention of the items. In order for the assessment to be valid, data must be obtained in such a way that will exclude the possibility the students to be untruthful. Anonymity was regarded as being important in reducing such possibility, allowing valid assessment.

Semantic problems occur in attitude measurements because instruments usually include words like often, seldom, frequently, and usually, which may have different meaning for different students. Therefore, clear terminology must be used, especially if students are unfamiliar with such instruments. Moreover, these problems should be reduced following Edwards' suggestions (Edwards, 1957).

Criterion inadequacy could be a problem with some measures. In some cases, for example, observing students performing experiments in the laboratory could clearly validate a measure of students' attainment of scientific skills. However, in most cases validity tests are not available. Gardner (1975b) suggested that a score from an attitude scale is meaningful when it reflects the respondents' position on well-defined attitude continuum. Furthermore, all the items within the scale must be related to a single attitude object. Ramsden (1998) has pointed out the use of "science" as an umbrella term to encompass biology, chemistry, physics, and possibly other areas. It has been suggested that the research of students' attitudes must focus on the separate disciplines within science rather than on science, because students (girls in particular) respond more positively to biological sciences than to physical sciences.

Another important problem is that of dimensionality. It has been reported (Gardner, 1975b; Rennie \& Parker, 1987), that many instruments have used a mixture of items, including several dimensions, but the analysis of the results was performed as if unidimensionality existed. Gardner (1975a) illustrated the weakness of this procedure by referring to the "dining-room table analogy": the length, weight, and reflectivity of a dining-room table can each be measured meaningfully, but adding these three variables together to form a "Dining Room Table Index" yields a meaningless, uninterpretable variable. He also suggested that attitudes toward science should be conceptualized as a multidimensional construct and this assumption must be tested using factor analysis. If factor analysis provides strong support for this conceptualization, interpretation of the results should be separately done for each dimension (Gardner, 1995).

In two important studies concerning the attitudes toward chemistry and science of secondary school students in Israel (1983) and the USA (1989), Menis argues that the assessment of students' attitudes toward chemistry and science should be concerned with at least three distinct referents. He identifies these referents as an attitude toward the importance of chemistry and science, an attitude toward chemistry and science as a career, and an attitude toward chemistry and science in school curriculum.

\section{THE GREEK CHEMISTRY CURRICULUM}

The interpretation of the results of an attitude study is related to the context of the existing curriculum. Thus, in this section a short description of the Greek chemistry curriculum is given. The Greek educational system at secondary level includes three years of middle school (grades 7-9) and three years of high school (grades 10-12). Grades 1-9 constitute the cycle of compulsory education. All students study chemistry as a separate discipline 
(core courses), at grades 8 and 9 one hour per week, at grade 10 two hours per week, and at grade 11 one hour per week. High school students wishing to study science or science-related fields at a University must additionally take up advanced chemistry courses at grades 11 and 12, which are taught two hours per week in each of these grades.

At grades 8 and 9, chemistry curriculum follows a macroscopic to microscopic approach. Macroscopic-microscopic approach refers to instructional methods that use examples of real-world or demonstrations to introduce chemistry topics followed by microscopic explanations using two-dimensional drawings of dots and circles to represent atoms, ions, and molecules (Brunce \& Gabel, 2002; Gabel, 1999; Johnstone, 1991). The chemical symbols are introduced as the language of chemical communication. The students are not asked to learn the use of chemical symbols, but only to recognize the chemical symbols of the most important chemical elements and compounds. For example, students recognize the symbol " $\mathrm{H}_{2} \mathrm{O}$ " as the chemical way to write "water."

At grades 10, 11, and 12, chemistry curriculum, both in core and advanced courses, emphasizes a linear development of chemical concepts with a symbolic approach. Linear development of chemical concepts refers to instructional methods that start from subjects that introduce first basic theoretical concepts of atomic theory and bonding on the microscopic level and proceed to subjects focusing on the macroscopic level (Gabel, 1999). Symbolic approach refers to instructional methods that use chemical and mathematical symbols and equations to represent the matter (Johnstone, 1991). One of the chemistry curriculum objectives is the ability of students to solve algorithmic chemistry exercises and problems. Students use chemical symbols to describe a chemical process as well as to extract the qualitative and quantitative information provided by a chemical formula.

The curriculum in Greece is centralized. Not only does the Greek government determine the national curriculum standards and content, but it also centralizes the textbooks, the teaching materials, and the pace of teaching. All schools throughout the country must follow the same curriculum and use the same educational materials authorized by the Ministry of Education. Lectures, including discussion and demonstrations, are common teaching methods used by the majority of teachers in middle and high schools. Laboratory chemistry courses are not included in the curriculum.

\section{PURPOSE OF THE STUDY}

The aim of this study was to examine the attitudes toward chemistry among 11th grade students. By the term "attitudes toward chemistry" we refer to positive or negative set of beliefs about chemistry and chemistry courses. In particular, we intended to investigate students' attitudes regarding

- The importance of chemistry in their life

- The importance of chemistry course

- The difficulty of chemistry course

- The interest of chemistry course

- The usefulness of chemistry course for their future career.

For reasons previously discussed, the first step of this study was to develop a valid and reliable questionnaire for measuring students' attitudes toward chemistry. Rather than translating an attitude questionnaire among those available in literature, we constructed a new questionnaire, in order to be more relevant to the curriculum and conditions applied in the Greek schools. 
Another purpose of this study was to answer the following questions:

1. Are there gender differences in students' attitudes toward chemistry?

2. Are there differences between students with different study specialization in their attitudes toward chemistry?

3. Is there significant correlation between students' attitudes toward chemistry and their achievement in chemistry?

\section{PROCEDURE}

\section{Construction of Test}

The procedure for test construction followed suggestions described by Likert (1932) and Edwards (1957). An attitude scale consists of a number of items that have been carefully edited and selected in accordance with certain criteria, as those items contained in any standardized psychological test. The items making up an attitude scale are called statements. Edwards developed a set of 14 "informal criteria" (suggestions) for developing such statements. According to Edwards' suggestions, we avoided statements that refer to the past and those that are capable of being interpreted as factual. We also avoided statements that may be interpreted in more than one way, and those containing universals such as all, always, none, and never, that they often introduce ambiguity. Particular care was taken to ensure that the content of items would be clearly understood by the respondents. Thus, the statements consisted of simple sentences not exceeding 20 words and the language was simple, clear, and direct. Abstract words were avoided, as well as sentences with double negatives. Finally, we tried to ensure that each statement was meaningful to respondents.

A panel of 14 scientists and science educators determined the content validity. This panel of judges was asked to

a. evaluate which statements clearly indicate favorable or unfavorable attitudes toward chemistry;

b. classify items to one of the following five thematic unities: the importance of chemistry in students' life, as well as the importance, the difficulty, the interest, and the usefulness of chemistry course for students' future career.

Item analysis based on an $80 \%$ agreement criterion was used to determine favorable or unfavorable statements. Items receiving less than $80 \%$ agreement were automatically excluded for future consideration. From the remaining items those that at least $60 \%$ of the judges classified in the same thematic unity were selected. This analysis yielded a total of 30 items, 6 for every thematic unity. From the 30 items retained for the inventory draft, 15 were considered to be favorable toward chemistry and thus agreement with them indicates a positive attitude, and 15 unfavorable toward chemistry that is agreement with them indicates a negative disposition toward chemistry.

Selected statements were then attached to a five-point Likert scale ranging from "strongly disagree" to "strongly agree" with "neither disagree nor agree" as the pivotal point of the scale. Moving from "strongly disagree" to "strongly agree," positive items were scored from 1 to 5 , respectively, while negative items were scored in the reverse order.

\section{The Pilot Study}

A pilot study was conducted using a target group of 70 students at 11th grade from an urban school in Athens. The evidence of construct validity was calculated with "item-total 
score" correlation using the Pearson's correlation coefficient $(r)$. Seven items out of 30 were described as marginally appropriate $(0.20<r<0.29) ; 5$ as appropriate $(0.30<r<0.39)$ and 18 as quite appropriate $(r>0.40)$. These results indicated that all items contribute to the validity of the instrument.

Data collected from the pilot study did not permit us to use factor analysis, as an adequate sample for explanatory factor analysis must include five respondents per variable and the minimum sample size of 200 (Gorsuch, 1983). The reliability of the scale was calculated by two different techniques: (a) split-half reliability and (b) reliability of "internal consistency." A comparison of the results of the present constructed scale's reliability test, listed in Table 1, with those reported by others (Misiti, Shringley, \& Hanson, 1991; Wareing, 1982), shows that the scale has a satisfactory and acceptable reliability.

\section{Main Study}

The participants were 576 high school students at the 11th grade, 16-17 years old. Intact classes of students drawn from seven schools in four towns in Greece served as subjects. At this grade, students are close to complete core chemistry courses.

The sample of students comprised 247 males and 329 females; 166 specialized in science and medicine, 213 in humanities, and 197 in engineering studies. Students specialized in science and medicine had also selected an advanced chemistry course. The sample percentages of males and females, as well as those of students in three study specializations were representative of the population at this grade. The questionnaires were distributed during the second half of the school year 2000-2001. Students were asked to provide information such as gender, study specialization, and their most recent grades of chemistry course. The test of reliability was repeated for these data and the results confirmed those obtained from the pilot study, as demonstrated in Table 2.

The assumption of the five dimensions was tested using factor analysis. We decided to carry out this procedure, not only to test the assumption of the existence of discrete factors but, primarily, to investigate the possibility that if such factors did exist, there might be significant differences in students' attitudes on one or more of these factors. The factor analysis was carried out using the procedure FACTOR in SPSS.

The correlation matrix for the variables item 1 to item 30 was computed. The Bartlett's test of sphericity gave a value of 6485.228 with a significance level $<0.001$, indicating the suitability of the factor model for the data under consideration. The Kaiser-Meyer-Olkin measure of sampling adequacy was also used. The value obtained in the current study was 0.938 , also indicating the appropriateness of the factor model.

\section{TABLE 1}

\section{Calculations of Reliability from Pilot Study Data}

\begin{tabular}{lr}
\hline Split-Half Reliability & \\
Correlation between forms & 0.79 \\
Guttman split-half & 0.88 \\
Alpha for part 1 (15 items in part 1) & 0.79 \\
Equal-length Spearman-Brown & 0.88 \\
Unequal-length Spearman-Brown & 0.88 \\
Alpha for part 2 (15 items in part 2) & 0.82 \\
Reliability of "Internal Consistency" & 0.89 \\
Cronbach's alpha & 0.89 \\
\hline
\end{tabular}




\section{TABLE 2}

\section{Calculations of Reliability from Main Study Data}

\begin{tabular}{lr} 
Split-Half Reliability & \\
Correlation between forms & 0.83 \\
Guttman split-half & 0.90 \\
Alpha for part 1 (15 items in part 1) & 0.81 \\
Equal-length Spearman-Brown & 0.91 \\
Unequal-length Spearman-Brown & 0.91 \\
Alpha for part 2 (15 items in part 2) & 0.87 \\
Reliability of "Internal Consistency" & 0.91 \\
Cronbach's alpha & 0.91 \\
\hline
\end{tabular}

Principal component analysis resulted in seven common factors with eigen values $>1$, which all together explain $58 \%$ of the variance. After examination of scree-plot, we decided to use four of the seven factors accounting for $47 \%$ of the variance. The four factors were subjected to a varimax rotation resulting in four independent factors.

An examination of the statements associated with each factor allows the underlying concept to be identified. The four concepts were identified as "the difficulty of chemistry course" (derived from items 7, 24, 17, 18, 26, and 2), "the interest of chemistry course" (derived from items 23, 21, 9, 25, 10, 3, 19, 1, and 16), "the usefulness of chemistry course for students' future career" (derived from items 22, 30, and 14), and "the importance of chemistry for students' life" (derived from items 12, 13, 15, 5, and 20). Four variables (subscales), "difficulty," "interest," "usefulness," and "importance" were defined on the basis of the results of the factor analysis. Cronbach's alpha was determined for each of them and the values obtained are presented in Table 3. The relative low value of Cronbach's alpha for "importance" is considered to be satisfactory as it is due to the fact that this factor explains a minor rate of variance.

\section{RESULTS AND DISCUSSION}

Table 3 provides a summary of 11th Grade students' scores on four variables. Data analysis has shown that students consider chemistry course to be neither difficult nor easy (neutral attitude). Their attitudes regarding interest of chemistry course is also neutral. On the other hand, they believe that chemistry course is not useful for their future career (negative attitude), but recognize the importance of chemistry in their life (positive attitude).

The mean and the standard deviation for the four variables according to sex, presented in Table 4, demonstrate that there was no significant difference in the level of interest, usefulness, and importance attributed to chemistry between boys and girls. Nevertheless,

\section{TABLE 3}

\section{Students' Attitudes Toward Chemistry}

\begin{tabular}{lcccccc}
\hline Variable & Min & Max & Mean & SD & Number of Items & Cronbach's Alpha \\
\hline Difficulty & 6 & 30 & 18.23 & 5.71 & 6 & 0.87 \\
Interest & 9 & 45 & 27.53 & 8.52 & 9 & 0.89 \\
Usefulness & 3 & 15 & 6.15 & 3.18 & 3 & 0.71 \\
Importance & 5 & 25 & 18.16 & 3.56 & 5 & 0.67 \\
\hline
\end{tabular}


TABLE 4

Attitude Toward Chemistry According to Sex

\begin{tabular}{|c|c|c|c|c|c|c|c|}
\hline \multirow[b]{2}{*}{ Variable } & \multicolumn{2}{|c|}{ Male $(N=247)$} & \multicolumn{2}{|c|}{ Female $(N=329)$} & \multirow[b]{2}{*}{$t$} & \multirow[b]{2}{*}{$d f$} & \multirow[b]{2}{*}{$p$} \\
\hline & Mean & SD & Mean & SD & & & \\
\hline Difficulty & 19.20 & 5.57 & 17.50 & 5.72 & 3.57 & 574 & $<0.001$ \\
\hline Interest & 28.04 & 8.14 & 27.14 & 8.79 & 1.27 & 574 & NS \\
\hline Usefulness & 6.34 & 2.92 & 6.01 & 3.36 & 1.24 & 574 & NS \\
\hline Importance & 18.32 & 3.71 & 18.03 & 3.44 & 0.96 & 574 & NS \\
\hline
\end{tabular}

girls held a significantly less positive attitude than boys regarding the difficulty of chemistry courses.

In Table 5 the mean and the standard deviation for the four variables according to study specialization are presented. From the one-way ANOVA data and especially from the Tukey's criterion, given in Table 6, the following conclusions are extracted:

- The students specializing in science-medicine held significantly more positive attitude regarding the four variables than students specializing in the other studies.

- The students specializing in humanities held significantly less positive attitude regarding the difficulty, interest, and usefulness attributed to chemistry than students specializing in engineering studies. However, there was no significant difference in attitude regarding the importance of chemistry by students specializing in humanities and engineering studies.

In an effort to obtain a relationship between students' attitudes toward chemistry and achievement in chemistry, Pearson correlation was carried out. The results are shown in Table 7. Clearly, a low positive correlation between students' achievement in chemistry and their attitudes toward chemistry was found. The relationship was stronger between students' achievement and their perceived difficulty of chemistry course.

Further analysis was conducted on the data to determine whether the achievement in chemistry accurately reflected the students' attitudes toward chemistry. Students' attitudes regarding difficulty, interest, usefulness of chemistry course, and importance of chemistry were chosen as predictor variables. Using the stepwise method of multiple regression, a significant model emerged $\left(F_{3,550}=45.441, p<0.001\right.$, Adjusted $\left.R^{2}=0.194\right)$. Significant variables are shown in Table 8 . This model accounts for $19.4 \%$ of variance, indicates dependency between "difficulty" and "interest," and offers a statistical ground for omitting the variable "interest" from this model.

\section{CONCLUSIONS AND REMARKS}

The present study provides an instrument for assessing students' attitudes toward chemistry with satisfactory degree of validity and reliability as supported by a variety of tests. More specifically, a factor structure was determined by exploratory factor analysis and the grouping of items was very satisfactory in terms of meaning of the grouping, which is an important step in establishing validity with factor analysis. In addition, the reliability of the factors allowed for their use and further exploration in the current study. Using this instrument the profile of attitudes toward chemistry among Greek students was identified for the first time. 


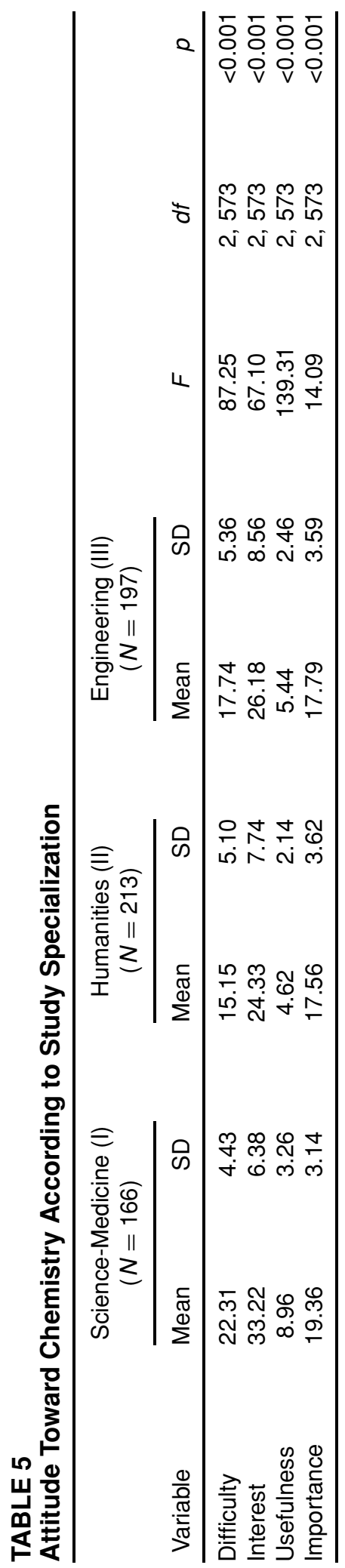


TABLE 6

Tukey's Criterion

\begin{tabular}{|c|c|c|c|c|c|c|c|c|c|}
\hline Variable & $\begin{array}{c}\text { Mean } \\
\text { Difference } \\
(\text { I-II) }\end{array}$ & $\begin{array}{l}\text { SD } \\
\text { Error }\end{array}$ & $p$ & $\begin{array}{c}\text { Mean } \\
\text { Difference } \\
(I-I I I)\end{array}$ & $\begin{array}{l}\text { SD } \\
\text { Error }\end{array}$ & $p$ & $\begin{array}{c}\text { Mean } \\
\text { Difference } \\
\text { (II-III) }\end{array}$ & $\begin{array}{l}\text { SD } \\
\text { Error }\end{array}$ & $p$ \\
\hline 110 & 80 & 0.52 & $<0.00$ & 4.57 & 0.53 & $<0.001$ & -2.22 & 0.50 & $<0.001$ \\
\hline Interest & 89 & 0.80 & $<0.001$ & 7.04 & 0.81 & $<0.001$ & -1.85 & 0.76 & $<0.05$ \\
\hline Usefulness & 4.33 & 0.27 & $<0.001$ & 3.52 & 0.28 & $<0.001$ & -0.81 & 0.26 & $<0.01$ \\
\hline Importance & 1.80 & 0.36 & $<0.001$ & 1.56 & 0.37 & $<0.001$ & -0.23 & 0.34 & NS \\
\hline
\end{tabular}

Students at 11th grade in Greek high schools consider the chemistry course neither difficult nor easy. Their attitudes regarding the difficulty of chemistry lessons are related to concepts, symbols, and problems' solving. It seems that students find the use and application of chemistry concepts and symbols more difficult than their understanding. The application of chemistry concepts and symbols depends on the students' ability to transfer from macroscopic level to symbolic level, from symbolic level to microscopic level, and vice versa (Dori \& Hameiri, 2003; Johnstone, 1991). The chemistry teacher can transfer rapidly from one level to the other, but students cannot do the same. In addition to the difficulties that students have in understanding and applying chemical concepts, such as atoms, molecules, mass, volume, and mole, they also have difficulties in solving chemical problems requiring mathematical skills. Thus, they consider difficult to recode and apply mathematical methods to chemistry problems.

The students' attitudes regarding the interest of chemistry course are also neutral. The content of chemistry curriculum, the chemistry lessons time (one hour per week), the methods of teaching chemistry in Greek schools, and the lack of laboratory experiments might be some of the reasons that form such attitudes. Schibeci and Riley (1986) showed that students' attitudes toward science are strongly influenced by what the teacher is doing in classroom. Freedman (1997) has found that a positive attitude toward science was related to the laboratory program. In Greece, chemistry is being taught theoretically without hands-on activities and this practice decreases students' interest for chemistry lessons.

The majority of students recognize that chemistry knowledge is useful to interpret aspects of their everyday life, but only $4 \%$ of students express their wish to continue chemistry studies. In Greece the profession of chemist is one of the less preferable. On the other hand, it is hopeful that most of the students believe that chemistry contributes in solving environmental problems and improves our lives. Greek students have a more positive attitude regarding the importance of chemistry rather than the use, difficulty, and interest of chemistry courses. These results are similar with those of Menis' study in Israel (1983).

\section{TABLE 7}

Pearson's Correlation Coefficients Between Achievement in Chemistry and Attitudes $(p<0.001, N=554)$

\begin{tabular}{lccccc}
\hline & Achievement & Difficulty & Interest & Usefulness & Importance \\
\hline Achievement & & 0.406 & 0.319 & 0.327 & 0.244 \\
Difficulty & 0.406 & & 0.712 & 0.437 & 0.373 \\
Interest & 0.319 & 0.712 & & 0.534 & 0.538 \\
Usefulness & 0.327 & 0.437 & 0.534 & & 0.266 \\
Importance & 0.244 & 0.373 & 0.538 & 0.266 & \\
\hline
\end{tabular}


TABLE 8

Multiple Regression of Achievement in Chemistry with Attitudes ${ }^{a}$

\begin{tabular}{lccccc}
\hline Predictor Variable & $\beta$ & SE & Beta & $t$ & $p$ \\
\hline Constant & 8.185 & 0.670 & & 12.213 & $<0.001$ \\
Difficulty & 0.168 & 0.025 & 0.297 & 6.688 & $<0.001$ \\
Usefulness & 0.175 & 0.043 & 0.174 & 4.075 & $<0.001$ \\
Importance & 0.080 & 0.038 & 0.087 & 2.095 & $<0.05$ \\
\hline
\end{tabular}

${ }^{a}$ Interest of chemistry course was not a significant predictor in this model.

Although there are no differences between boys' and girls' attitudes regarding the interest, usefulness, and importance of chemistry, girls, more than boys, tend to express negative attitudes regarding the difficulty of chemistry courses. It is possible that these attitudes of girls are due to "social norms" or in other words to social stereotypes. Girls' beliefs that chemistry is difficult reflect stereotypes like "boys are born to be scientists or chemists." As most of the books, films, television programs, and newspaper articles highlight male science figures, the gender-equity should be a goal of science education. Our results do not agree with those of Menis' study in Israel (1983), showing significant differences between boys' and girls' attitudes toward chemistry. Israeli boys showed more positive attitudes regarding the interest, use, and importance of chemistry. However, our study shows that Greek girls and boys perceive the importance of chemistry almost equally. Francis and Greer have found analogous results regarding the science-related attitudes among pupils in Northern Ireland (1999).

Our study suggests that the correlation between attitudes toward chemistry and achievement in chemistry is low up to moderate. The correlation is stronger between difficulty and achievement, indicating that a positive attitude regarding difficulty of chemistry course is more necessary for students in achieving high scores. In addition, a model for achievement's prediction from attitudes has arisen, but its predictive value is still problematic because of the low percentage of variation that it explains (adjusted $R^{2}=0.194$ ). This results from the fact that there are high performance students with less positive attitudes than low performance students.

Most people in the science education community tend to agree to a greater or smaller extent that negative attitudes toward chemistry and science cause a crucial problem. Further research in attitudes will contribute to the explanation of the persisting problem of alienation from chemistry among young people. If carefully focused and designed, attitude research could go one step further and provide bases on which correct decisions will be taken about aspects for classroom practice. This might get more young people choosing to study chemistry subjects, feeling that chemistry really does offer them something useful and interesting. Such positive attitudes, cognitive skills, and knowledge will help the future citizens being continuously informed, making judgments and taking decisions on issues related to chemistry.

\section{APPENDIX: QUESTIONNAIRE}

Students were requested to respond to the following statements on a Likert five point scale.

1. I like chemistry course more than the others.

2. Chemical symbols are like Chinese to me.

3. I would like to have chemistry lessons more often. 
4. The progress of chemistry is responsible for many environmental problems.

5. Chemistry knowledge is useful to interpret many aspects of our everyday life.

6. Chemistry course is not related to the other courses.

7. I solve chemistry exercises very easily.

8. Chemistry course helps the development of my conceptual skills.

9. During chemistry lessons, I am bored.

10. Chemistry knowledge will be useless after my graduation.

11. Chemistry knowledge is essential for understanding other courses.

12. The progress of chemistry improves the quality of our lives.

13. Chemistry is our hope for solving many environmental problems.

14. My future career is independent from chemistry knowledge.

15. The progress of chemistry contributes to the development of a country.

16. Chemistry is a very sophisticated subject for our compulsory education.

17. I make many efforts to understand chemistry.

18. I find the use of chemical symbols easy like walk-over.

19. The profession of a chemist is one of the less attractive.

20. Every citizen must have chemistry knowledge.

21. I hate chemistry courses.

22. Chemistry knowledge is necessary for my future career.

23. I would like to have fewer chemistry lessons.

24. I understand the chemistry concepts very easily.

25. I find the chemistry course very interesting.

26. When I try to solve chemistry exercises, my mind goes blank.

27. People are indifferent to chemistry applications.

28. The progress of chemistry worsens the conditions of living.

29. I am incapable of interpreting the world around me using chemistry knowledge.

30. I would like to become a chemist when I finish school.

The authors wish to express their sincere thanks to Dr. K. Mylonas for useful suggestions and discussions.

\section{REFERENCES}

Aiken, L. R., \& Aiken, D. R. (1969). Recent research on attitudes concerning science. Science Education, 53, 295-305.

Brunce, D. M., \& Gabel, D. L. (2002). Differential effects on the achievement of males and females of teaching the particulate nature of chemistry. Journal of Research in Science Teaching, 39, 911-927.

Dori, Y. J., \& Hameiri, M. (2003). Multidimensional analysis system for quantitative chemistry problems: Symbol, macro, micro and process aspects. Journal of Research in Science Teaching, 40, 278-302.

Eagly, A. H., \& Chaiken, S. (1993). The psychology of attitudes. Fort Worth, TX: Harcourt Brace Jovanovich.

Edwards, A. L. (1957). Techniques of attitude scale construction. New York: Appleton-Century Crofts.

Francis, L. J., \& Greer, J. E. (1999). Attitude toward science among secondary school pupils in Northern Ireland: Relationship with sex, age and religion. Research in Science and Technological Education, 17(1), 67-74.

Freedman, M. P. (1997). Relationship among laboratory instruction, attitude toward science and achievement in science knowledge. Journal of Research in Science Teaching, 43(4), 343-357.

Gabel, D. L. (1999). Improving teaching and learning through chemistry education research: A look to the future. Journal of Chemical Education, 76, 548-554.

Gardner, P. L. (1975a). Attitudes to science: A review. Studies in Science Education, 2, 1-41. 
Gardner, P. L. (1975b). Attitude measurement: A critique of some resent research. Education Research, 17, 101-105.

Gardner, P. L. (1995). Measuring attitudes to science: Unidimensionality and internal consistency revisited. Research in Science Education, 25, 283-289.

Germann, P. J. (1988). Development of the attitude toward science in school assessment and its use to investigate the relationship between science achievement and attitude toward science in school. Journal of Research in Science Teaching, 25(8), 689-703.

Gorsuch, R. L. (1983). Factor analysis (2nd ed.). Hillsdale, NJ: Lawrence Erlbaum.

Greenfield, T. A. (1996). Gender, ethnicity, science achievement, and attitudes. Journal of Research in Science Teaching, 33(8), 901-933.

Haladyna, T., \& Shauhnessy, J. (1982), Attitudes toward science: A review. Science Education, 66(4), 547-563.

Johnstone, A. H. (1991). Why is science difficult to learn? Things are seldom what they seem. Journal of Computer Assisted Learning, 7, 75-83.

Jones, G. M., Howe, A., \& Rua, M. J. (2000). Gender differences in students' experiences, interests, and attitudes toward science and scientists. Science Education, 84, 180-192.

Koballa, T. R. (1988). Attitude and related concepts in science education. Science Education, 72, $115-126$.

Koballa, T. R., \& Crawley, F. E. (1985). The influence of attitude on science teaching and learning. School Science and Mathematics, 85, 222-232.

Laforgia, J. (1988). The affective domain related to science education and its evaluation. Science Education, 72, 407-421.

Likert, R. (1932). A technique for the measurement of attitudes. Archives of Psychology, 140, 1-55.

Menis, J. (1983). Attitudes towards chemistry as compare with those towards mathematics, among tenth grade pupils (aged 15) in high level secondary schools in Israel. Research in Science and Technological Education, 1(2), 185-191.

Menis, J. (1989). Attitudes towards school, chemistry and science among upper secondary chemistry students in the United States. Research in Science and Technological Education, 7, 183-190.

Misiti, F., Shringley, R., \& Hanson, L. (1991). Science attitude scale for middle school students. Science Education, 75, 525-540.

O’Brien, J., \& Porter, G. C. (1994). Girls and physical science: The impact of a scheme of intervention projects on girls attitudes to physics. International Journal of Science Education, 16(3), 327-341.

Petty, R. (1995). Attitude change. In A. Tesser (Ed.), Advanced social psychology. New York: McGraw-Hill.

Ramsden, J. M. (1998). Mission impossible?: Can anything be done about attitudes to science? International Journal of Science Education, 20, 125-137.

Rennie, L. J., \& Parker, L. H. (1987). Scale dimensionality and population heterogeneity: Potential problems in the interpretation of attitude data. Journal of Research in Science Teaching, 24, 567577.

Schibeci, R. A. (1983). Selecting appropriate attitudinal objectives for school science. Science Education, 67, 595-603.

Schibeci, R. A., \& Riley, J. P. II. (1986). Influence of student's background and perceptions on science attitudes and achievement. Journal of Research in Science Teaching, 23, 177-187.

Simpson, R., \& Oliver, S. (1985). Attitude toward science and achievement motivation profiles of male and female science students in grades six through ten. Science Education, 69, 511-526.

Wareing, C. (1982). Developing the WASP: Wareing attitude toward science protocol. Journal of Research in Science Teaching, 19, 639-645.

Weinburgh, M. (1995). Gender differences in student attitudes toward science: A meta-analysis of the literature from 1970 to 1991. Journal of Research in Science Teaching, 32, 387-398.

Wilson, V. L. (1983) A meta-analysis of the relationship between science achievement and science attitude: Kindergarten through college. Journal of Research in Science Teaching, 20(3), 839-850. 